\title{
Identification of Pollution Patterns and Sources in a Semi-Arid Urban Stream
}

\author{
Vassiliki Markogianni ${ }^{*}$, Evangelia Anastasopoulou', \\ Alexandros Tsoupras'², Elias Dimitriou' \\ 1 Institute of Marine Biological Resources and Inland Waters, Hellenic Centre for Marine Research, $46.7 \mathrm{~km}$ of \\ Athens-Sounio Av., 19013, Anavissos, Attica, Greece \\ 2 Directorate of Environment and Climate Change, Region of Attica, Polytechniou 4, 10433, Athens, Greece \\ * Corresponding author's e-mail: vmarkogianni@hcmr.gr
}

\begin{abstract}
The impact and occurrence of human-induced pollution sources have been investigated in one of the few remaining urban streams located in Attica, Greece. Baseline information is provided on the presence and concentration of physicochemical parameters, nutrients, total coliforms, hydrocarbons and phenols in 12 key points along the Pikrodafni stream. The aim was to evaluate the relative importance of key water quality variables and their sources. Indicator substances (i.e. concentrations of nitrate, ammonium, phosphate and total coliforms in certain stations indicating wastewater exposure; PAHs indicating petroleum sources) successfully related the water quality variables to pollution sources. Furthermore, a pollution pressure map has been developed with the activities identified from in-situ visits and Google Earth surveys, while the statistical analysis (CA and PCA) has contributed to the further exploration of the relative magnitude of pollution sources effects. Our results underline initially the importance of diffuse pollution management accompanied by the necessity for continuous environmental monitoring and the application of legal and environmental restoration actions if water quality is to be improved according to WFD 2000/60/EC.
\end{abstract}

Keywords: pollution sources, urban stream, water quality, Water Framework Directive

\section{INTRODUCTION}

During the last decades, sustainable development has been an important topic in most political arenas, and the agenda has been expanded to include the protection of environmental amenities and recreational resources in metropolitan areas, which are important elements of "urban sustainability" [Wheeler, 2000 in Dimitriou et al., 2014]. The global population shifted rapidly from rural to mostly urban during the last century, with the urban population increasing from $14 \%$ of the world's population (224 million) in 1900 to more than $50 \%$ in 2015 (3.9 billion).

Urbanization as a social, economic and territorial transition process, puts a considerable stress on the socio-economic and ecological systems which has been of interest to the scientific community for many years. Recent studies [Ea- gleson, 2002; Groffman et al., 2002; Karr, 1999; Lowrance, 1998; Pinkham, 2000; Platt, 2006; Walsh et al., 2005; Zalewski, 2013 in Meltem and Azime, 2017] declare that the accumulation of people in cities has extensive and profound impact on riverine systems.

According to Pinkham [2000], the characteristics and functions of urban rivers, which are one of the most modified aquatic ecosystems, are gradually weakened or lost. Throughout the history, the expansion of anthropogenic activities led riverine systems to be polluted, culverted, buried or changed (due to the alterations of the hydro morphological structure) which resulted in damaged and fragmented aquatic ecosystems [Meltem and Azime, 2017]. For example, the increases in total discharge, peak discharge, and flashiness have been reported in urban streams as impervious land cover increases within the wa- 
tershed [Nelson et al., 2009; Schoonover, Lockaby, \& Helms, 2006; Wu et al., 2013 in Wu et al., 2015]. Floods are some of the most devastating, yet common, natural disasters affecting the urban areas [Yoon et al., 2014; Zheng et al., 2009 in Yoon et al., 2016]. The impact of climate change on the flood risk presented by urban rivers is of particular interest because such areas are typically densely populated [Birkmann et al., 2010; Feyen et al., 2008; Ford and Smit, 2004; Kim et al., 2013; Merz et al., 2010; Yoon et al., 2014 in Yoon et al., 2016]. The exacerbation of urban river flooding by climate change will not only cause a significant loss of life and property, but will also contribute to the public health and social problems [Oven et al., 2012 in Yoon et al., 2016]. It is therefore vital that society develops urban river management systems that can cope with and reduce the impacts of the climate change, including the flood damage [Kim et al., 2013; Schirmer and Schuchardt, 2001; Wardekker et al., 2010; Yoon et al., 2014; Zbigniew and Takeuchi, 1999 in Yoon et al., 2016].

Moreover, elevated concentrations of nutrients, metals and sediments have also been reported in urban streams [Deemer et al., 2012; Grayson et al., 1996; Hatt et al., 2004 in Wu et al., 2015]. Phosphorus and nitrogen from fertilizers applied to lawns, sediment and salts from roads, and increased runoff from roofs delivered to streams rapidly via storm sewers have been identified as potential contributors to the stream degradation in the urban areas [Adachi \& Tainosho, 2005; Fissore et al., 2011; Negishi et al., 2007; Ragab et al., 2003 in Wu et al., 2015]. Given the changes in urban stream hydrology as well as habitat and water quality, the biological communities are also likely to be affected [Walsh et al., 2005 in Wu et al., 2015].

In the urban areas, with the improvement of river environments and the adjustment of the urban economy and land use, the redevelopment of urban waterfronts became a global phenomenon after the 1970s and 1980s [Zhang et al., 2002 in Jiang et al., 2016]. The river protection and restoration movement, combined with positive changes in greenway planning, gradually almost became a how-to guide for open space planning, after the 1980s [Fabos, 2004 in Jiang et al., 2016]. As far as the urban river corridor restoration is concerned, the ecological environment assessment of river corridors has become an important tool and process for protecting and making river policies. River health assessment involves a com- prehensive evaluation of river hydrology, biology, and habitat conditions, providing basic data and information feedback for adaptive management of rivers to promote their sustainable development [Karr, 1999; Leppard \& Munawar, 1992; White \& Ladson, 1999 in Jiang et al., 2016].

Within the European Union, the Water Framework Directive 2000/60/EC [WFD, 2000 in Dimitriou et al., 2014] has been the major legislative driver that specifies that hydromorphology should underpin good ecological status in streams and rivers. Hence, the WFD and the relevant national legislation impose the continuous monitoring of water bodies and the maintenance of their good ecological status within a specific timetable. The restoration efforts in the urban streams have primarily focused on channel reconfiguration and in-stream habitat improvements increasing heterogeneity, for instance, by adding meanders and physical structures such as wood, boulders, and artificial riffles [Larson et al., 2001; Miller et al., 2010 in Dimitriou et al., 2014].

Most urban streams in Attica region, Greece, have been significantly modified due to intense urbanization.

Pikrodafni stream is one of the few remaining urban streams of Attica, which is preserved in an almost natural state and constitutes a valuable opportunity for restoration, improvement, and maintenance. Even though Pikrodafni stream is subjected to significant anthropogenic pressures, such as destruction of riparian zone and illegal sewage disposal, it still retains some of its important hydromorphological and biological characteristics [Dimitriou et al., 2014]. Additionally, there is little reliable data on the environmental/ ecological condition of the stream, its hydrologic behavior, flood risk, and the riparian zone that could be used for multiple purposes. Consequently, environmental monitoring of the Pikrodafni stream is necessary to carry out the proper scientific planning for its restoration, and environmentally friendly exploitation. Thus, the main objective of this study is to analyze a large number of environmental parameters (physicochemical, nutrients, total coliforms, hydrocarbons and phenols) at key areas along the stream and associate them with the spatiotemporal distribution of the main pollution pressures. In conjunction with the identification of pollution sources, specific measures are proposed to reduce the water pollution impacts and restore the ecological status of the stream at a favorable level. 


\section{METHODOLOGY}

\section{Study area}

Pikrodafni stream is located in the southeastern part of Attica and has a total length of approximately $9.3 \mathrm{~km}, 6 \mathrm{~km}$ of which still retains natural features, while the rest is confined as an artificial canal (Figure 1). The natural environment of the stream is generally degraded due to the uncontrolled urban constructions along the whole riparian zone, illegal waste disposal at certain points, as well as the sewage pipelines and the human interventions to the streambed [Dimitriou et al., 2014]. However, there are still typical riverine habitats, such as riffles, pools, runs and the existence of natural substrate, as well as diverse aquatic vegetation, that demonstrate some ecological integrity in many parts of the river. Pikrodafni stream flows during almost the entire year and is characterized by the presence of meanders, floodplain shores, and small pools [Dimitriou et al., 2014].

\section{Water sampling and quality classification system}

Water samples were collected on the field at a monthly basis from October 2016 to March 2017, in a network of twelve (12) stations (Figure 1). The samples were collected and preserved by the addition of $\mathrm{HgCl}_{2}$ while the transfer to the Hellenic Centre for Marine Research (HCMR) laboratories was realized immediately after the sampling effort (in the same day). Sokratous and Verginas stations were added in the sampling network in December 2016, following the recommendations of the region of Attica due to illegal pollutants disposal, identified there in the past. This sampling network was established to cover the stream spatially, taking into account the anthropogenic pressures, the different habitats, and the hydromorphological conditions of the stream. The portable instrument Horiba U-50 Multiparameter water quality checker was used to measure the physicochemical parameters e.g. water temperature, $\mathrm{pH}$, electrical conductivity, dissolved oxygen concentration and total dissolved

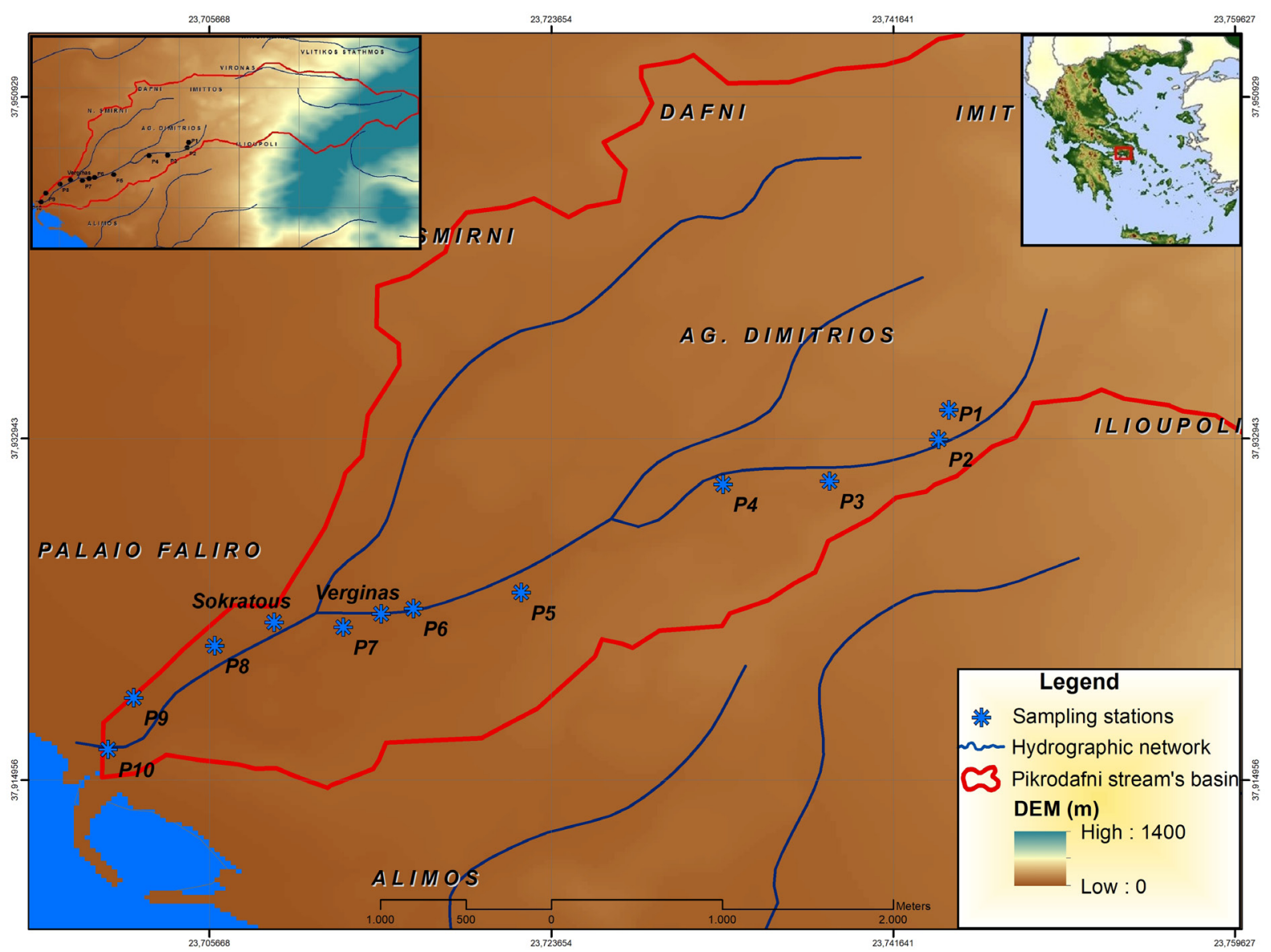

Figure 1. Pikrodafni stream basin and sampling stations. 
solids (T.D.S.). The water samples were filtered through $0.45 \mu \mathrm{m}$ cellulose acetate filters that had been pre-cleaned with $10 \%$ hydrochloric acid $(\mathrm{pH}$ $=2$ ) followed by rinsing with Milli-Q water. The chemical analyses followed for major ions and nutrients (nitrates, nitrites, ammonium, sulphates, phosphates, silicates, chlorides, carbonates, ions of calcium, magnesium, sodium and potassium).

The surface water samples for PAHs concentrations were collected by means of a water sampling device consisting of a weighted bottle holder with a clean amber-glass bottle [UNEP, 1984]. The samples were filtered through pre-cleaned glass fibre filters (Whatman GF/F, $0.7 \mu \mathrm{m}$ ).

Water sampling for the analysis of microbiological parameters was carried out using $2 \mathrm{~L}$ sterile plastic containers, which were transported within 4 hours to the respective, certified, laboratory for analysis. The membrane filtration method was employed for the determination of total coliforms, where a sufficient amount of water is filtered through a $0.25 \mu \mathrm{m}$ filter.

In order to classify the physicochemical status of the river sites, the river nutrient classification system (NCS) [Skoulikidis et al., 2006; Table 1] was applied for nutrients and the Norwegian system for dissolved oxygen [Cardoso et al., 2001; Table 1].

\section{Chemical analyses}

All the analyses were performed at HCMR laboratories. Nutrients $\left(\mathrm{NO}_{2}^{-}, \mathrm{PO}_{4}{ }^{3-}, \mathrm{NH}_{4}^{+}\right)$, were measured photometrically, in the soluble fraction, using an ion analyzer (Metrohm), an automatic analyzer Radiometer and the photometer Merck Nova 400. For the determination of total coliforms, the APHA 9222B standard analysis method was employed, which uses the M-Endo Agar Les as a nutrient substrate, incubation temperature of $35^{\circ} \mathrm{C}$ and incubation time of $22 \mathrm{~h}$.

Concerning PAHs analysis, after the addition of internal standards (phenanthrene-d10, pyrene- d10, chrysene-d12, perylene-d12), the filtrates were extracted, within a few hours after filtration, with $n$-hexane. The $n$-hexane extracts were dried over sodium sulphate, reduced to $2 \mathrm{ml}$ in a rotary evaporator and stored in the refrigerator until the analysis. After the addition of internal standards, the filters were extracted with dichloromethane in a sonicator bath for $30 \mathrm{~min}$. In the laboratory, the extracts were further reduced to a final volume of $50 \mu \mathrm{l}$ with the aid of a stream of pure nitrogen and PAH analyses were conducted by gas chromatography - mass spectrometry (Hewlett Packard 6890 GC-MS) in full scan mode. A CPSil 8 MS analytical column $(30 \times 0.25 \mathrm{~mm}$ i.d. $\times$ $0.25 \mu \mathrm{m}$ film thickness) was used and the oven temperature was programmed from $60^{\circ} \mathrm{C}(1 \mathrm{~min})$ to $290^{\circ} \mathrm{C}(10 \mathrm{~min})$ at $15^{\circ} \mathrm{C} / \mathrm{min}$. The $\mathrm{PAH}$ quantitation was based on the internal standards added before the extraction. The recoveries were higher than $70 \%$. Procedural blanks were processed in the same manner as real samples and they were below $20 \%$ of the abundance of analytes. The detection limit for each PAH was $0.01 \mathrm{ng} / 1$ [Hatzianestis and Sklivagou, 2002].

The colorimetric method 4 aminoantipyrine was applied for the determination of phenols in river waters. The sample is collected after extraction with chloroform and then analyzed by a Uvvis Perkin Elmer spectrophotometer at a wavelength of $460 \mathrm{~nm}$. The method is based on the reaction of phenolic compounds with 4 aminoantipyrine, in the presence of potassium ferrocyanide, where the sample obtains a stable reddishbrown color, the intensity of which is proportional to the concentration of the phenolic compounds present [Standard Methods, method 5530, 2005].

\section{Statistical analysis}

In order to detect and identify the main pollution patterns and sources along the Pikrodafni stream, multivariate statistical methods such as cluster analysis (CA) and principal component

Table 1. River nutrient and dissolved oxygen classification system [Skoulikidis et al., 2006; Cardoso et al., 2001]

\begin{tabular}{|c|c|c|c|c|c|c|}
\hline Compound & Units & High & Good & Moderate & Poor & $\mathrm{Bad}$ \\
\hline \multicolumn{7}{|c|}{ [Skoulikidis et al., 2006] } \\
\hline $\mathrm{NO}_{3}^{-}$ & $\mathrm{mg} / \mathrm{l}$ & $<0.97$ & $0.97-2.66$ & $2.67-5.75$ & $5.76-797$ & $>797$ \\
\hline $\mathrm{NO}_{2}^{-}$ & $\mathrm{mg} / \mathrm{l}$ & $<0.01$ & $0.01-0.026$ & $0.027-0.099$ & $0.1-0.23$ & $>0.23$ \\
\hline $\mathrm{NH}_{4}^{+}$ & $\mathrm{mg} / \mathrm{l}$ & $<0.031$ & $0.031-0.077$ & $0.078-0.26$ & $0.27-0.64$ & $>0.64$ \\
\hline $\mathrm{PO}_{4}^{3-}$ & $\mathrm{mg} / \mathrm{l}$ & $<0.22$ & $0.22-0.32$ & $0.33-0.506$ & $0.507-1.05$ & $>1.05$ \\
\hline \multicolumn{7}{|c|}{ [Cardoso et al., 2001] } \\
\hline Dissolved oxygen & $\mathrm{mg} / \mathrm{l}$ & $>9$ & $>6.4$ and $<9$ & $>4$ and $<6.4$ & $>2$ and $<4$ & $<2$ \\
\hline
\end{tabular}


analysis (PCA) have been utilized. The descriptive statistics of the stream's water quality data and basic statistical elaboration were conducted using the IBM SPSS software v23.

\section{Cluster analysis}

A cluster analysis categorized with Euclidean distance, using the PRIMER v.6 statistical package [Clarke and Gorley, 2006], was conducted to identify groups of stations with similar environmental characteristics. Hierarchical CA starts with each case in a separate cluster and joints the clusters together step by step until only one cluster remains and is typically illustrated by a dendrogram (tree diagram) [McKenna Jr., 2003]. The Euclidean distance usually gives the similarity between two samples, and a distance can be represented by the difference between the analytical values from the samples [Otto, 1998]. Prior to the analysis, dissolved oxygen, nutrients, total coliforms and polycyclic aromatic hydrocarbons (PAHs) concentrations were log-transformed and normalized.

\section{PCA}

The analysis of factors with the principal component method is used to study the relationships between quantitative variables by grouping them into factors. The procedure with which the analysis of the main components (SPSS) is conducted goes through Factor Analysis [Gallego et al. 2002]. Multivariate analysis of data was carried out using statistical software. The data introduced for the analysis of factors were derived from all the sampling campaigns that took place at stations P1-P10, in Pikrodafni stream. The parameters considered included nutrients, main ions, aliphatic hydrocarbons, physicochemical parameters, total coliforms, total phenols and certain heavy metals $(\mathrm{Cd}, \mathrm{Pb}, \mathrm{Zn}, \mathrm{Cu}, \mathrm{Ni}, \mathrm{Co}, \mathrm{Mn})$. The average value of each chemical parameter was calculated for each station separately.

Initially, the data was evaluated in order to determine whether or not it followed a normal distribution by applying the Test of Normality Kolmogorov-Smirnov. Most parameters did not follow regular distribution and data was transformed $(\log 10)$ across all variables. Furthermore, suitability tests were conducted, including KMO (Kaiser-Meyer-Olkin) measure, which must be greater than 0.5 and Bartlett's test of sphericity.
The table of Communalities was created (Correlation coefficient of the variables to the factors derived from the analysis) in which each variable should have a value greater than 0.5 , otherwise it may be necessary to exclude the variables that do not meet this criterion. Certain variables were removed from the analysis since they did not meet some of the criteria mentioned above (e.g. Ca, $\mathrm{HCO}_{3}, \mathrm{pH}$, discharge).

\section{Detection of pollution sources}

The point pollution sources are the most important type of pressures along the stream [Dimitriou et al., 2014] due to the heavily urbanized character of the catchment. It is very difficult to identify the existing pollution sources that pose direct threat on the stream's quality since many activities are not officially registered while others that are registered have illegal, underground pipeline connections to the stream. Thus, in this study a pollution pressure map has been developed with the activities identified from in-situ visits and Google Earth surveys. This map has only been used to explain the spatial distribution of the main pollutants concentrations along the stream and not for polluters identification. This is something that needs more detailed investigations that utilize, amongst others, georadar and pipelines robot surveys since a large proportion of the hydrographic network consists of buried canals and pipelines.

\section{RESULTS}

\section{Physicochemical parameters fluctuations}

The Dissolved Oxygen (DO) concentrations in the study area ranged from $5.18(\mathrm{P} 7,10 / 2016$ - moderate quality) to $16.7 \mathrm{mg} / 1$ (P8, 03/2017 high quality), with an average value of $9.4 \mathrm{mg} / \mathrm{l}$, which characterizes the average water quality as high [Cardoso et al., 2001; Table 1, Table 2]. The upstream stations (P1, P4, P6) and the downstream stations (P7 and P8-P10), have higher dissolved oxygen levels than P2, P3, P5 and Sokratous stations. However, all stations have an average good quality based on DO while the worse status is observed in Verginas station which is marginally characterized as of good quality, since the average value equals to $6.9 \mathrm{mg} / 1$ [Cardoso et al., 2001].

The $\mathrm{NO}_{3}^{-}$concentrations illustrated relatively high values in all stations that ranged from 17.12 (P2, 
02/2017) to $97.8 \mathrm{mg} / 1$ (Verginas, 01/2017), with an average value of $41.5 \mathrm{mg} / \mathrm{l}$, resulting in the characterization of all water samples as of bad quality. $\mathrm{NH}_{4}^{+}$ concentrations illustrated also high variations ranging from $0.012(\mathrm{P} 10,11 / 2016)$ to $19.2 \mathrm{mg} / \mathrm{l}$ (Sokratous, $01 / 2017$ ), with a mean value of $1.2 \mathrm{mg} / \mathrm{l}$. High variations were observed in $\mathrm{PO}_{4}^{3-}$ concentrations that ranged from 0.018 (P7, 02/2017) to $4.9 \mathrm{mg} / \mathrm{l}$ (Sokratous, $01 / 2017$ ) with mean value $0.82 \mathrm{mg} / \mathrm{l}$.

The highest average nitrate, ammonium, and phosphate concentrations were measured at P8P10 and at Sokratous-Verginas stations, and they were classified as of bad quality based on the nutrient classification system [Skoulikidis et al., 2006; Table 1].

The concentrations of total coliforms also illustrated very high variability at a spatiotemporal basis, ranging from $3(\mathrm{P} 7,03 / 2017)$ to $1,800,000$ cfu/ $100 \mathrm{ml}$ (Sokratous, 01/2017) with a mean value equal to $41,233.9 \mathrm{cfu} / 100 \mathrm{ml}$ (Table 2).

Total polycyclic aromatic hydrocarbons (TPAH) concentrations also indicated the existence of heavy pollution and ranged from $15.1(\mathrm{P} 7,11 / 2016)$ to $3,663 \mathrm{ng} / \mathrm{l}(\mathrm{P} 10,12 / 2016)$, with a mean value of $369.1 \mathrm{ng} / \mathrm{l}$. Additionally, phenol's concentrations presented a relatively low variation that ranged from 5.29 (P3, 01/2017) to $48.29 \mu \mathrm{g} / \mathrm{l}(\mathrm{P} 8,02 / 2017)$, with a mean value of $19.09 \mu \mathrm{g} / 1$ (Table 2 ).

The highest values of total phenols were recorded at stations P7 (41.6 $\mu \mathrm{g} / \mathrm{L}$ November 2017) and P8 (48.29 $\mu \mathrm{g} / 1$ February 2017), while the highest annual average concentration was recorded at station P7 $(30.06 \mu \mathrm{g} / \mathrm{l})$. However, this value does not exceed the limit of annual average concentration (AAC) established in the European Union and also adopted in Greece, regarding the concentration of total phenols in surface waters according to the environmental quality standards (EQS) of specific pollutants, which is $50 \mu \mathrm{g} / 1$ [Government Gazette 2010; Directive, 2008/105 EC]. The annual average concentration was recorded lower than the limit mentioned above, at all stations.

\section{Temporal fluctuations of pollutants}

In order to analyze the temporal pollution changes, the water sampling results were divided seasonally, into autumn (Oct-16, Nov-16, Dec-16) and winter (Jan-17, Febr-17, Marc-17) periods.

The distribution of nitrate concentrations during the autumn samplings, indicated that P8 following by $\mathrm{P} 1$ and Verginas stations presented the highest average values equal to $51.9 \mathrm{mg} / \mathrm{l}, 49.6$ $\mathrm{mg} / \mathrm{l}$ and $49.5 \mathrm{mg} / \mathrm{l}$, respectively. The lowest average nitrate value was detected at Sokratous station $(22.7 \mathrm{mg} / \mathrm{l})$. On the other hand, the highest measured $\mathrm{NO}_{3}^{-}$concentration during winter was detected at Sokratous station (77.8 mg/l), followed by Verginas $(58.8 \mathrm{mg} / \mathrm{l})$ and P8-P9-P10 stations. In general, all $\mathrm{NO}_{3}^{-}$concentrations along the Pikrodafni stream during both seasons are characterized by high values, indicating their bad water quality.

The highest phosphate concentrations during both winter and autumn were also observed at stations Sokratous and Verginas (bad water quality), whereas during autumn P9 and P10 also displayed bad quality and during winter-poor water quality. The monthly fluctuations of phosphates are not as high as in nitrate concentrations, with the median values range slightly below $1 \mathrm{mg} / \mathrm{l}$.

The ammonium concentrations during winter are also notably high at downstream stations (bad quality in Verginas, Sokratous, P8-P10) while the same pattern is apparent during autumn with the exception of P8 station, which demonstrates poor water quality. Another difference detected, regarding the ammonium distribution, is the water quality of stations $\mathrm{P} 1$ and $\mathrm{P} 3$, which is poor and good in winter, respectively, but high during autumn. Moreover, the sampling efforts of October and November 2016 presented the lowest concentrations, whereas December demonstrated the greatest range of values.

Seasonally, the highest values and fluctuations occur in December, January and February

Table 2. Descriptive statistics of the under study water quality parameters along the Pikrodafni stream

\begin{tabular}{|l|c|c|c|c|c|c|c|c|}
\hline & Units & $\mathrm{N}$ & Minimum & Maximum & Mean & Median & $\begin{array}{c}\text { Std. } \\
\text { Deviation }\end{array}$ & Variance \\
\hline Dissolved oxygen & $\mathrm{mg} / \mathrm{l}$ & 68 & 5.18 & 16.7 & 9.4 & 9.3 & 2.24 & 4.996 \\
\hline $\mathrm{NO}_{3}$ & $\mathrm{mg} / \mathrm{l}$ & 68 & 17.12 & 97.78 & 41.48 & 41.11 & 15.79 & 249.2 \\
\hline $\mathrm{NH}_{4}{ }^{+}$ & $\mathrm{mg} / \mathrm{l}$ & 68 & 0.012 & 19.16 & 1.2 & 0.053 & 3.54 & 12.5 \\
\hline $\mathrm{PO}_{4}{ }^{3-}$ & $\mathrm{mg} / \mathrm{l}$ & 68 & 0.018 & 4.9 & 0.82 & 0.53 & 0.84 & 0.71 \\
\hline Total coliforms & $\mathrm{cfu} / 100 \mathrm{ml}$ & 68 & 3.0 & 1800000 & 41233.9 & 525 & 232348 & 539855824 \\
\hline Total phenols & $\mu \mathrm{g} / \mathrm{l}$ & 60 & 5.296 & 48.3 & 19.1 & 17.6 & 9.67 & 93.4 \\
\hline Total PAH & $\mathrm{ng} / \mathrm{l}$ & 67 & 15.1 & 3663 & 369.1 & 117.7 & 653.4 & 426899.3 \\
\hline
\end{tabular}


2017, for most of the above-mentioned parameters (Figure 2), while October and November illustrate the lowest values and fluctuations, on average, for all parameters. Sokratous and Vergina stations are presented as outliers and extremes in all parameters, apart from Phenols, which indicates the significant pollution loads that are associated with these sites (Figure 2).

The temporal distribution of total coliform concentrations reveals great differences between the average monthly levels. The greatest total coliform values were observed in December 2016 (also illustrating the greatest range of values) while the samplings of October and November 2016 are characterized by the lowest values. Sokratous site is either an extreme or outlier in four out of six monitoring months. At upstream stations (P1-P4), as well as at P10 and Verginas stations, greater concentrations have been measured during winter than in autumn, whereas the same case is observed at P5, P8 and P9 stations during autumn.

Regarding the temporal distribution of PAHs along the Pikrodafni stream, greater values are mostly measured at upstream stations (P1-P6) and P9-P10 stations during autumn while the greatest values are detected at Verginas, Sokratous and P8 stations during winter samplings. December 2016 is the month with the highest PAHs levels and fluctuations while in October 2016 the lowest levels have been observed (Figure 2).

The highest average phenol value was recorded during November 2016 and the lowest in March $2017(10.59 \mu \mathrm{g} / 1$ and $6.96 \mu \mathrm{g} / 1$ respectively). The pollution of phenols to surface waters is known to be seasonal and the highest values are being recorded during the winter period since they are the main components of olive mill waste waters, but they can also be found in other waste discharges, e.g. from wine or wood industries.

\section{Spatial pollution changes}

The spatial distribution of nitrates along the Pikrodafni stream indicates that values are increasing from upstream to downstream stations (except for P7 station), with the highest concentrations at Verginas and Sokratous stations (Figure 3). Furthermore, all stations are characterized as of bad quality for Nitrate during both winter and autumn seasons. The increasing spatial trend from upstream towards downstream is more pronounced in the winter period while during autumn, a relatively low fluctuation around
$40 \mathrm{mg} / \mathrm{l}$ is observed in all stations. Sokratous site presents the largest difference in $\mathrm{NO}_{3}{ }^{-}$concentrations between the 2 sampling seasons while stations P9, P10 (downstream) and P5 have almost stable concentrations throughout the entire study period. These spatiotemporal patterns indicate that the sources of $\mathrm{NO}_{3}^{-}$relevant pollutants are widely spread in the majority of the geographical segments of the stream. It seems that Verginas and Sokratous stations are amongst the most polluted ones but even the upstream stations (P1-P3) illustrate $\mathrm{NO}_{3}^{-}$values above $20 \mathrm{mg} / \mathrm{l}$ which are typical of severely impacted surface water bodies.

The patterns similar to the $\mathrm{NO}_{3}^{-}$concentration are also observed in $\mathrm{NH}_{4}^{+}$levels that increase from upstream towards downstream with Verginal and Sokratous stations presenting the highest values. The stations P1 to P6 (upstream and middle parts of the catchment) are characterized as of moderate quality for most of their samples while the downstream stations are of bad and poor quality regarding $\mathrm{NH}_{4}^{+}$levels (Figure 3 ).

Phosphates are likewise increasing, with Verginas and Sokratous stations demonstrating the highest values, while the neighboring stations (P9, P10) are affected as well, characterizing their water quality as bad. Upstream (P1-P4) and P7 stations demonstrate a moderate water quality while P5-P6 and P8 a poor quality, respectively.

The spatial trend of the physicochemical quality in Pikrodafni stream indicates a general degradation along the stream with some exceptions. The intermediate sites (P3, P4, P6 and P7) are classified as of moderate physicochemical status while the rest of the stations presented poor physicochemical status. Moreover, Sokratous and Verginas stations were characterized as of poor physicochemical status, since the concentrations of all nutrients exceed the relevant threshold values due to the significant pollution loads that are evident in these stations. Moreover, the poor quality that is encountered in the deltaic sites (P8, P9 and P10) indicates potential impacts mainly from domestic sewage which is also confirmed by the relatively high concentrations of Total coliforms in these sites, especially at P10.

Concerning the PAHs concentrations, the values are decreasing from upstream to downstream (P1-P6), indicating a PAH source at P1-P3 stations, and are increasing again at Verginas, Sokratous, P9 and P10 stations where the highest concentrations appear. Maximum PAH concentrations and specifically petroleum-originated com- 
a)

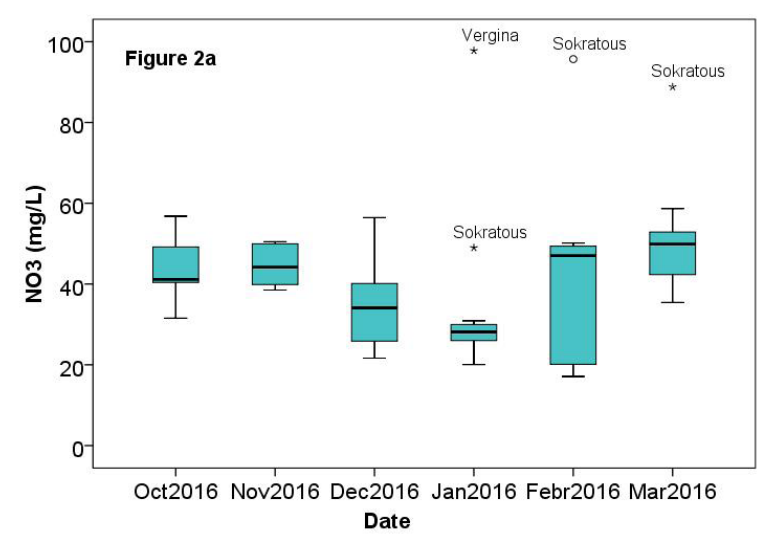

c)

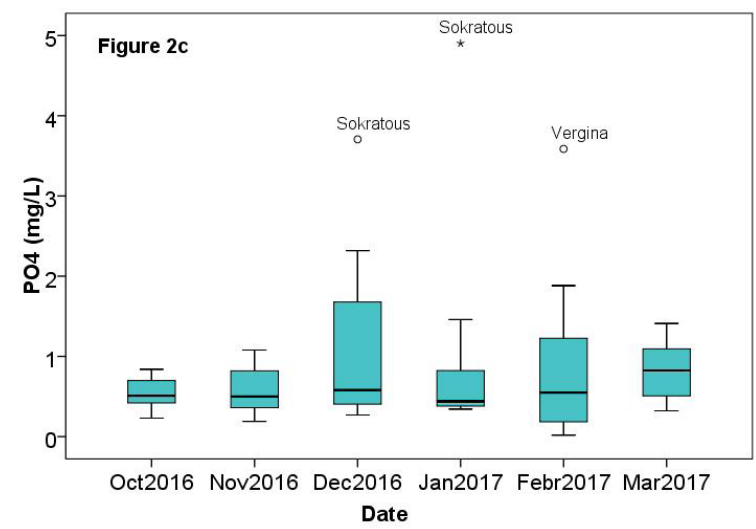

e)

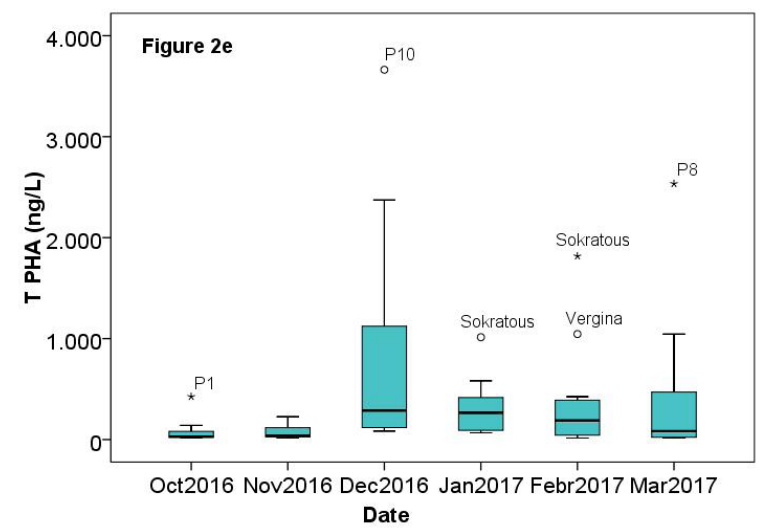

b)

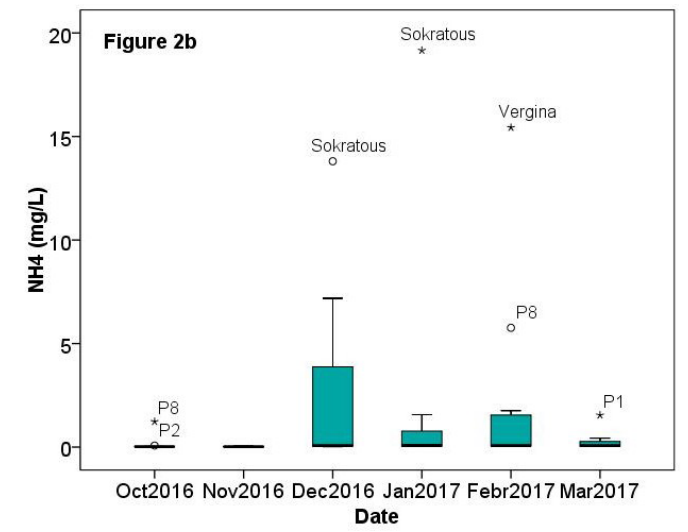

d)

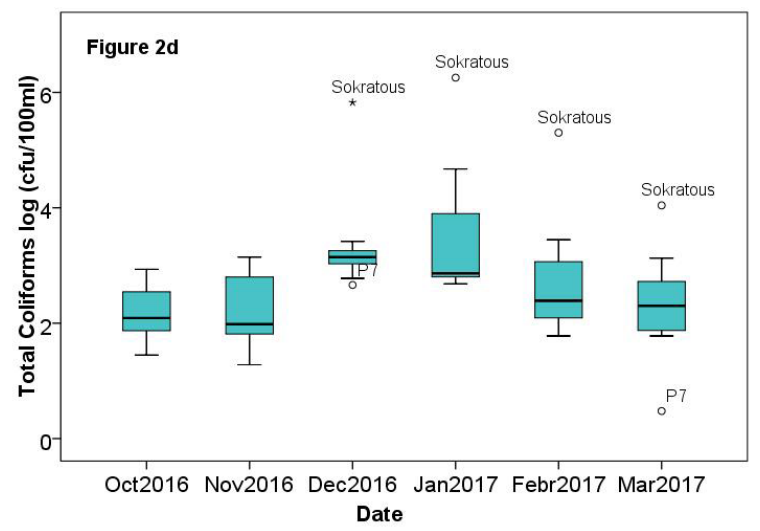

f)

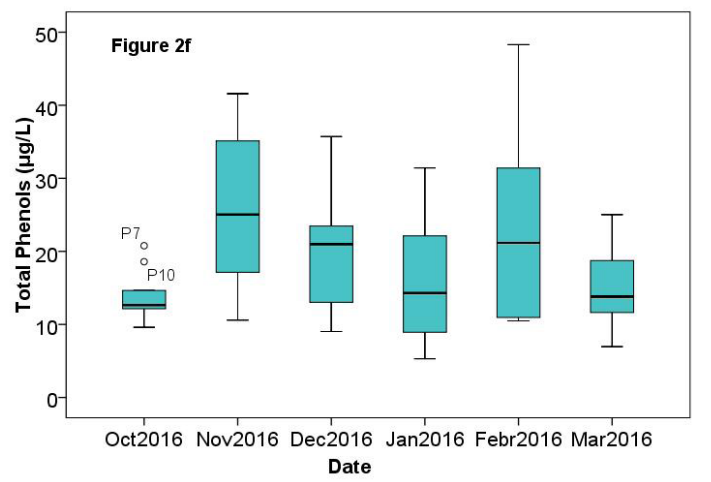

Figure 2. Temporal distribution of a) $\mathrm{NO}_{3}^{-}$, b) $\mathrm{NH}_{4}^{+}$, c) $\mathrm{PO}_{4}{ }^{3-}$, d) total coliforms, e) total $\mathrm{PAH}$ and f) total phenols concentrations in Pikrodafni stream

pounds predominated at Sokratous station while extremely high PAH concentrations, (petroleum originated), were observed at Verginas station. The afore-mentioned maximum concentrations were followed by those measured at P1-P2, P8, P9 and P10 (high) stations. Therefore, three major sources of PAHs are identified based on the measurements. The first one is located upstream of P1 site, the second one in sites Verginas and Sokratous while the third one in the very downstream part of the stream (P9 and P10).
According to the microbiological analysis and the relevant characterization of freshwaters [EPA, 2003b], the maximum average concentrations of Total Coliforms are detected at downstream stations and especially at Verginas station $(9,967.5 \mathrm{cfu} / 100 \mathrm{ml})$ and P10 (8,290 cfu/100 ml), which are characterized as highly contaminated and contaminated, respectively, according to the EPA standards $(10,000 \mathrm{cfu} / 100 \mathrm{ml})$. P8 station is characterized as moderately contaminated, since its concentrations are within the ranges of 
a)

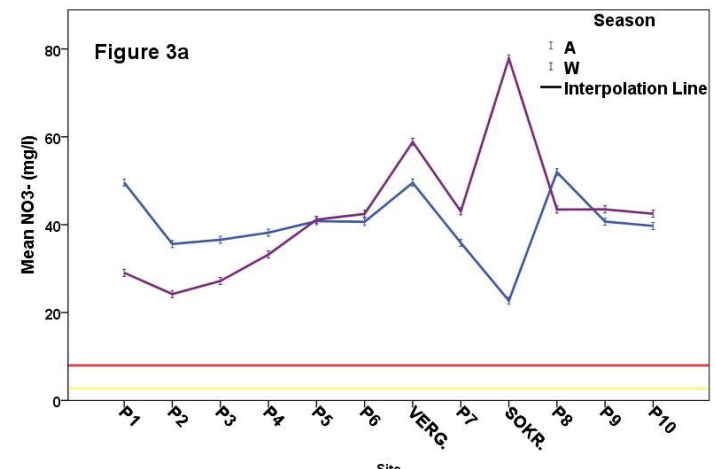

c)

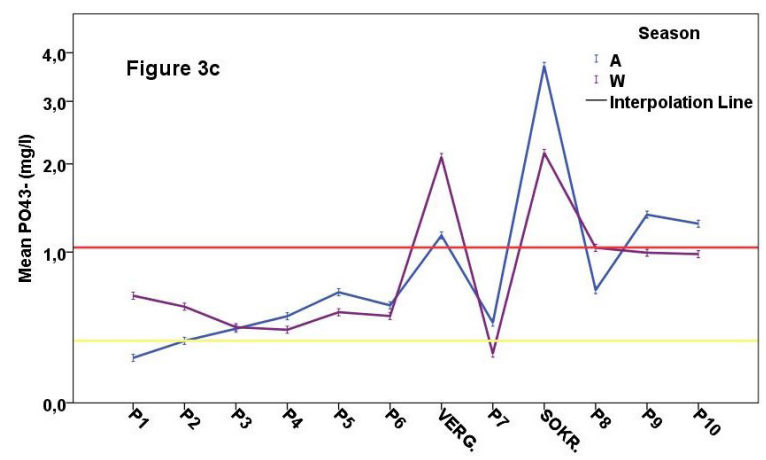

e)

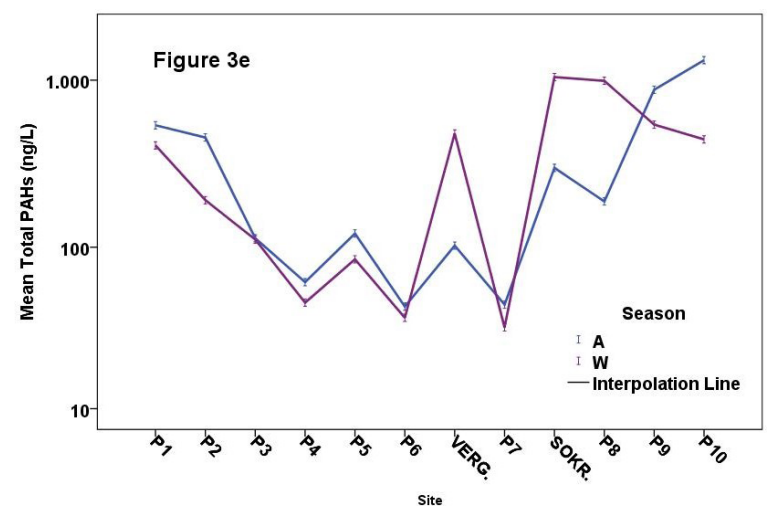

b)

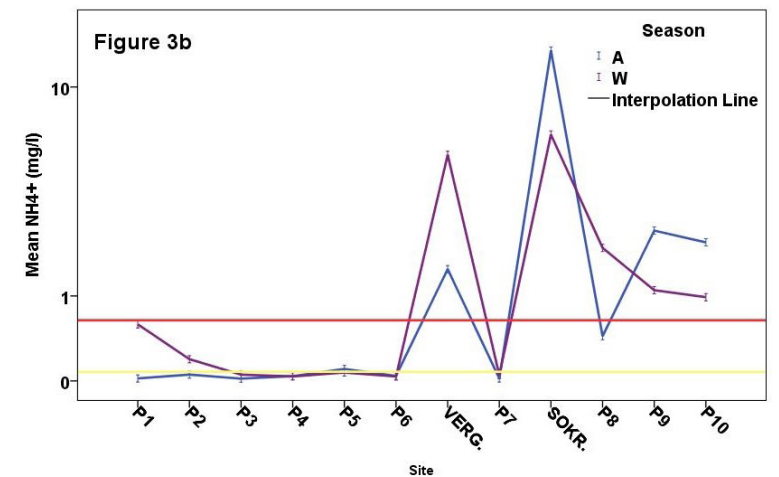

d)

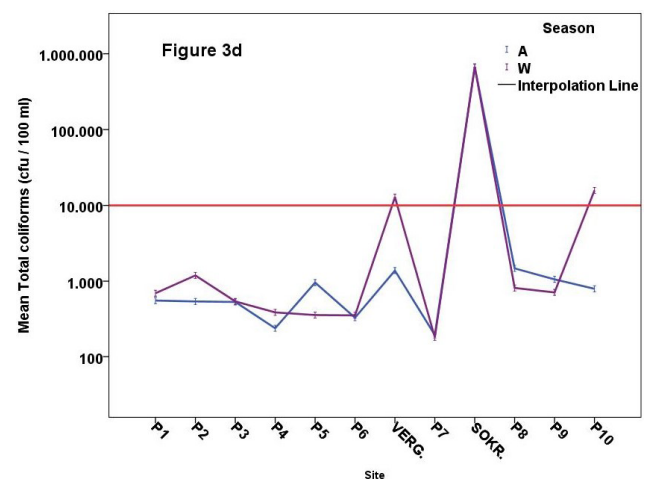

f)

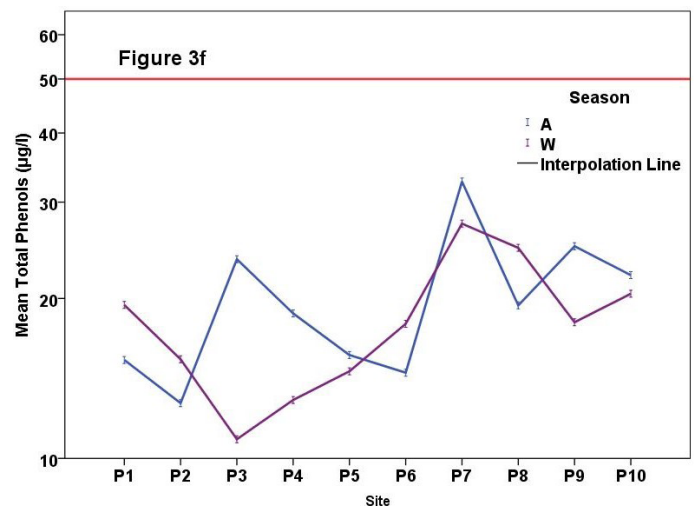

Figure 3. Spatial distribution of a) $\mathrm{NO}_{3}^{-}$, b) $\mathrm{NH}_{4}^{+}$, c) $\mathrm{PO}_{4}{ }^{3-}$, d) Total Coliforms, e) Total PAH and f) Total Phenols concentrations in Pikrodafni stream (Yellow and red lines represent the threshold values for each nutrient in order for every water sample to be classified as of moderate and bad chemical quality, respectively [Skoulikidis et al., 2006]

1,000 to $5,000 \mathrm{cfu} / 100 \mathrm{ml}(1,143.3 \mathrm{cfu} / 100 \mathrm{ml})$. Total coliforms' concentrations greater than 100 $\mathrm{cfu} / 100 \mathrm{ml}$ are continuously repeated along the stream indicating possible uncontrolled urban sewage disposal in many different spots, the most important of which are Verginas, Sokratous and P10 stations (Figure 3). The most extreme Total Coliform average value in both autumn and winter seasons has been observed in Sokratous station which reaches $670,250 \mathrm{cfu} / 100 \mathrm{ml}$ ).

Regarding phenols, the upstream sections of Pikrodafni stream (P1-P6) do not have high val- ues since the AAC ranged from 14.09-17.42 $\mu \mathrm{g} / 1$. On the contrary, phenols were detected at the downstream section of the studied stream (P7$\mathrm{P} 10)$ where the corresponding values ranged from 21.24-30.06 $\mu \mathrm{g} / \mathrm{l}$.

\section{Cluster analysis}

A cluster analysis categorized with Euclidean distance and accompanied by the physicochemical status of each site was computed in order to identify the groups of stations with similar envi- 
ronmental characteristics. Cluster analysis was applied for autumn and winter seasons and revealed four main groups of stations that vary according to season (Figures $4 \mathrm{a}$ and $4 \mathrm{~b}$ ).

The first group of sites in autumn (Figure 4a) included the sampling stations in the upstream and middle part of the stream (P1-P2, P3-P4-P5 and P6-P7) which all have a moderate quality status, apart from site $\mathrm{P} 1$ that has good quality status. Then, another group of sites includes the stations in the downstream part of the stream (P8 - Verginas and P9 - P10), which illustrate poor water quality status. Sokratous is the only station that is not grouped with any other site due to the intense HCs and urban waste pollution that distinguish it from the rest of the sites.

The identified clusters are slightly different during winter (Figure $4 \mathrm{~b}$ ) since Verginas (bad quality status) and Sokratous (poor quality status) sites are grouped together while the rest of the clusters are almost the same as in autumn. The only dif- ference is that $\mathrm{P} 3$ site is clustered together with the upstream stations (P1 and P2) that illustrate a poor-quality status (in autumn P1 had a good and P2 moderate quality status). Therefore, during winter, the pollution pressures increase, even at the upstream part of the stream which leads to a degradation of the quality status in relation to autumn. Moreover, from the cluster analysis becomes evident that Pikrodafni stations and the stream is split in 3 main zones (upstream, middle stream and downstream) with the exception of Verginas and Sokratous stations that are autonomously classified due to their poor and bad quality status.

\section{Pollution sources' impact}

From the statistically significant correlations (Pearson) between the concentrations of the chemical parameters, after the Varimax rotation with the resulting factors, we observe the following: Four main components were generated, each one was

a)

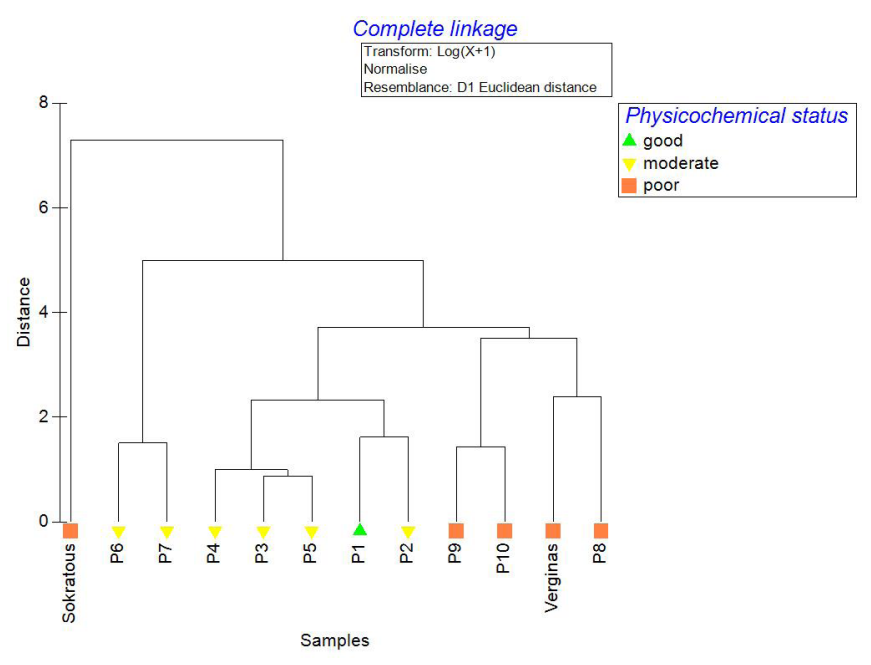

b)

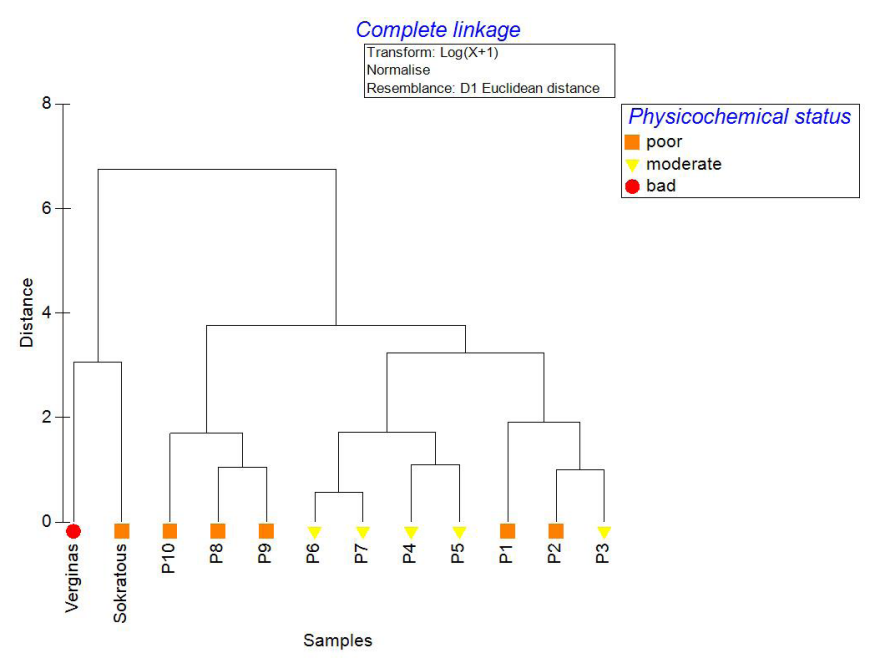

Figure 4. Cluster analysis dendrogram for a) autumn and b) winter periods. 
characterized by eigenvalue $>1$. The first explains $36.7 \%$ of the fluctuation, the second $-30.4 \%$, the third $-14.2 \%$ and the fourth $-10.6 \%$ of the fluctuation. The four factors that emerged, account for $91.95 \%$ of the variance. This value is sufficient to accept the analysis. The correlation of chemical parameters with the factors/main components resulting from the multifactorial analysis is shown in Table 3.

The parameters strongly related with the first principal component are the following: $\mathrm{PO}_{4}{ }^{3-}$, $\mathrm{NH}_{4}^{+}, \mathrm{NO}_{2}^{-}$, total coliforms and certain heavy metals $(\mathrm{Mn}, \mathrm{Co}, \mathrm{Ni}, \mathrm{Pb}, \mathrm{Cu})$. These variables are strongly related to each other [coef. $>0.77$ ] and determine the quality status of the stations to a greater extent than the other parameters (Table 3). Total coliforms, are strongly correlated with phosphates and ammonia, compounds that are detected in urban waste waters. More specifically, phosphates occur in great concentrations in urban waste water and values up to $26 \mathrm{mg} / \mathrm{l}$ have been recorded in untreated urban wastes [Shakunthala, 2010]. NH4, on the other hand, usually occurs when organic matter decomposes under low oxygen conditions and total coliforms are present in urban wastes at elevated concentrations [Melian, 2000]. Thus, the pollution from the first principal component could be attributed to urban waste waters. The variables grouped in the second component accounted for $30.4 \%$ of the total variance and include $\mathrm{NO}_{3}^{-}, \mathrm{SO}_{4}{ }^{2-}, \mathrm{Na}, \mathrm{Cl}$, dissolved oxygen and phenols which are strongly related to each other (coeff.> 0.70). The second factor had high loadings for nitrates, sodium and phenols, indicating that the pollution sources could include cultivated soil runoff and industrial wastes. In this area, the gardening activities are carried out close to the stream in which people cultivate vegetables and aesthetic flora, while small scale wood industry exists mainly in the upper and middle parts of the catchment. The third principal component which explained $14.2 \%$ of the total variance had strong positive loadings for electrical conductivity, salinity and total dissolved solids, parameters strongly related and could well originate from sea spray that certainly affects the middle and downstream parts of the study area. Aliphatic hydrocarbons are very slightly correlated with the other parameters in the third component. Potassium and zinc, belong to the fourth component, differentiate from the other parameters indicating an origin from the ground since zinc can be introduced into water naturally by erosion of minerals from rocks and soil [www.atsdr.cdc.gov].
Table 3. Correlation of chemical parameters with factors resulting after Varimax rotation. Principal Component Analysis.

\begin{tabular}{|c|c|c|c|c|}
\hline \multirow{2}{*}{ Component } & \multicolumn{4}{|c|}{ Rotated Component Matrix ${ }^{a}$} \\
\hline & 1 & 2 & 3 & 4 \\
\hline $\mathrm{Mn}$ & $0 . .961$ & $0 . .089$ & $0 . .208$ & $-0 . .078$ \\
\hline Co & $0 . .931$ & $-0 . .069$ & $0 . .062$ & $-0 . .261$ \\
\hline $\mathrm{Ni}$ & $0 . .907$ & -0.140 & 0.217 & 0.142 \\
\hline Colif & 0.899 & 0.069 & 0.041 & 0.169 \\
\hline $\mathrm{Pb}$ & 0.890 & 0.067 & 0.195 & -0.139 \\
\hline $\mathrm{Cu}$ & 0.888 & 0.199 & 0.294 & 0.088 \\
\hline $\mathrm{NO}_{2}^{-}$ & 0.867 & 0.169 & 0.304 & -0.263 \\
\hline $\mathrm{NH}_{4}^{+}$ & 0.863 & 0.442 & 0.150 & -0.107 \\
\hline $\mathrm{PO}_{4}{ }^{3-}$ & 0.775 & 0.485 & -0.015 & 0.314 \\
\hline $\mathrm{NO}_{3}^{-}$ & 0.115 & 0.934 & 0.171 & 0.072 \\
\hline $\mathrm{SO}_{4}{ }^{2-}$ & 0.110 & 0.922 & -0.004 & 0.326 \\
\hline $\mathrm{Na}$ & 0.228 & 0.900 & -0.113 & 0.342 \\
\hline $\mathrm{Cl}$ & 0.247 & 0.872 & -0.164 & 0.363 \\
\hline DO & 0.245 & 0.859 & -0.228 & -0.060 \\
\hline $\mathrm{Mg}$ & -0.472 & 0.746 & -0.043 & 0.424 \\
\hline phenol & 0.026 & 0.708 & -0.162 & -0.063 \\
\hline EC & 0.311 & -0.065 & 0.941 & 0.049 \\
\hline T.D.S. & 0.393 & -0.045 & 0.899 & -0.114 \\
\hline Sal & 0.117 & -0.568 & 0.795 & -0.102 \\
\hline Aliphatic & 0.531 & -0.081 & 0.560 & -0.522 \\
\hline $\mathrm{K}$ & -0.009 & 0.580 & -0.109 & 0.763 \\
\hline $\mathrm{Zn}$ & -0.064 & 0.630 & -0.026 & 0.754 \\
\hline \multicolumn{5}{|c|}{$\begin{array}{l}\text { Extraction Method: Principal Component Analysis. } \\
\text { Rotation Method: Varimax with Kaiser Normalization. }\end{array}$} \\
\hline \multicolumn{5}{|c|}{ a. Rotation converged in 7 iterations. } \\
\hline
\end{tabular}

The results are also presented in a diagram of factors where each variable is represented in space (Figure 5). Overall, the analysis shows that total coliforms are associated with phosphates and certain heavy metals such as $\mathrm{Co}, \mathrm{Ni}, \mathrm{Mn}, \mathrm{Cu}$ and $\mathrm{Pb}$. Also, the variables $\mathrm{PO}_{4}{ }^{3-}, \mathrm{NH}_{4}^{+}, \mathrm{NO}_{2}^{-}$, total coliforms and $\mathrm{Mn}, \mathrm{Co}, \mathrm{Ni}, \mathrm{Pb}, \mathrm{Cu}$ which are grouped in the first component, were the main influential factor in physicochemical water sample properties. This factor indicates a negative influence on surface water quality due to urban waste disposal. We can also conclude that most of the toxic heavy metals examined are also closely associated with total coliforms and, therefore, the urban waste is the major source of pollution in the area.

\section{Map of pollution sources}

Along the course of Pikordafni stream, a series of activities that can consitute significant pollution sources exist, such as wood, textiles and cosmetics industries, car repair shops, gas stations, parking lots and wastewater flood discharge stations, (Figure 6). 


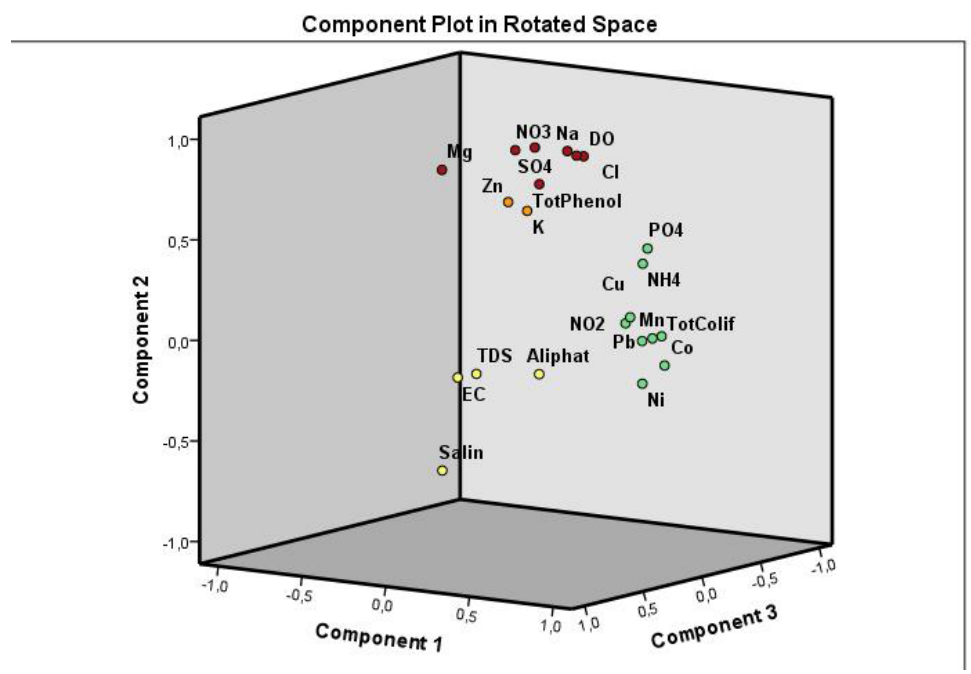

Figure 5. Diagram of Factors of all chemical parameters in Pikrodafni stream

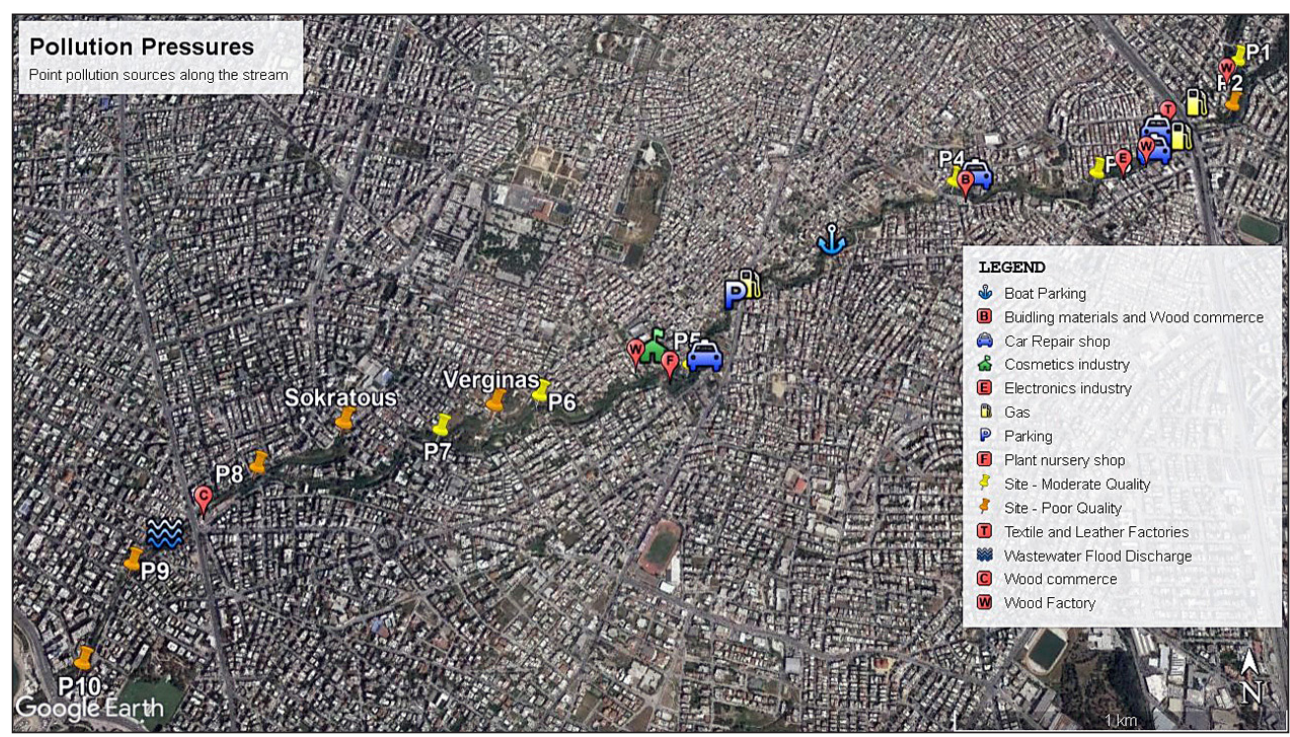

Figure 6. Point pollution pressures along Pikrodafni stream

The main pollution related activities have been identified in the upstream part of the stream (mainly between sites P2 and P3) and include car repair shops, gas stations, wood and textile industry. A car repair shop and parking lots, as well as building materials shop exist just before $\mathrm{P} 4$ site, while a cosmetics industry, a plat nursery shop and boat and car repair facilities have been detected close to P5 (Figure 6). A wasterwater flood pumping station is located upstream of site P9, which normally operates under flood conditions and discharges urban waste in the stream to avoid sewage network overspill. Given the average physicochemical status of the sampling sites, it seems that $\mathrm{P} 2$ (poor status) receives significant pollution pressures that are subsequently are slightly reduced through the natural attenuation mechanisms of the stream until P7 site (moderate status). Downstream of P7, all stations illustrate poor quality status which means that Sokratous and Verginas pipelines/canals are the main contributors of pollutants in the lower part of the catchment.

\section{CONCLUSIONS}

Urban stream research is an important tool that can illustrate the impacts on ecosystem deterioration [Kasahara and Hill, 2008] from the combination of urban physicochemical processes [Kaushal and Lewis, 2005], hydrological alterations [Konrad and Booth, 2002], and the biological community [An et al., 2006; Choi et al., 2011]. Numerous case studies of successful rehabilitation in developed countries have been extensively recorded. Urban landscapes are complex systems for which the identification of Drivers, Pressures 
and Impacts that are necessary to design restoration measures, can be proven difficult. A diverse group of scientists including environmentalists, engineers and biologists, but also governmental authorities, and residents needs to be involved to create an effective rehabilitation plan.

We conducted this study examining Pikrodafni stream to quantify the direct and indirect effects among the social system, the terrestrial landscape, and the stream processes regarding water quality, including physicochemical parameters, nutrients, total coliform, total phenols and PAHs concentrations. This approach allowed us to identify the important pollutant sources and the relative magnitude of their effects.

This study is a scientific attempt to monitor the water quality status of Pikrodafni stream, in the context of EU Water Framework Directive. During this research, there has been an effort to detect the most significant pollution pressures. The results indicated the water quality degradation of the stream, particularly at downstream stations, between the stations Sokratous and P10, probably triggered by illegal sewage and industrial waste disposal. Moreover, the average nitrate concentrations of all sampling periods were significantly high in all stations, characterizing the water as of bad quality, while the total physicochemical status of all sampling stations is characterized as of moderate and poor, based on the dissolved oxygen and nutrient concentrations. Taking into account the PAH concentrations, relatively high or very high and extremely high values (Verginas station) (petroleum originated compounds) were detected along the stream during all sampling campaigns, indicating significant degradation originating from petroleum sources. These results indicate the necessity for continuous environmental monitoring at certain points of the stream and legal investigations to identify the specific polluters and undertake the necessary legal and environmental restoration actions.

\section{Acknowledgments}

This study was conducted under the research project "Improving knowledge and increasing awareness wetland restoration in Attica regionEEA", funded by Region of Attica and resulted from the collaboration between the Hellenic Ornithological Society and the Institute of Marine Biological Resources and Inland Waters of the Hellenic Centre for the Marine Research (Greece).

\section{REFERENCES}

1. Adachi K., Tainosho Y. 2005. Single particle characterization of size-fractionated road sediments. Applied Geochemistry, 205, 849-859.

2. An K.G., Lee J.Y., Bae D.Y., Kim J.H., Hwang S.J., Won D.H., Lee J.K., Kim C.S. 2006. Ecological assessments of aquatic environment using multi-metric model in major nationwide stream watersheds. J. Korean Water Qual. 22, 796-804. (in Korean).

3. Birkmann J., Garschagen M., Kraas F., Quang N. 2010. Adaptive urban governance: new challenges for the second generation of urban adaptation strategies to climate change. Sustain. Sci. 5 (2), 185-206.

4. Cardoso A.C., Duchemin J., Magoarou P., Premazzi G. 2001. Criteria for the identification of freshwater subject to eutrophication. Their use for the implementation of the "Nitrates" and Urban Waste Water Directives. EUR 19810 EN, EU - JRC, 87.

5. Choi J.W., Kumar H.K., Han J.H., An K.-G. 2011. The development of a regional multimetric fish model based on biological integrity in lotic ecosystems and some factors influencing the stream health. Water Air Soil Pollut., 217, 3-24.

6. Clarke K.R., Gorley R.N. 2006. PRIMER v6: User Manual/Tutorial. PRIMER-E, Plymouth, p. 192.

7. Deemer B., Goodwin K., Lee T., Birchfield M. K., Dallavis K., Emerson J., et al. 2012. Elevated nitrogen and phosphorus concentrations in urbanizing southwest Washington streams. Northwest Science, 864, 237-247.

8. Dimitriou E., Markogianni V., Mentzafou A., Karaouzas I., Zogaris S. 2014. Ecological status assessment of Pikrodafni stream Attica, Greece, restoration and management measures. Desalination and Water Treatment, 1-8.

9. Directive $2008 / 105 /$ EC of the European Parliament and of the Council of 16 December 2008 on environmental quality standards in the field of water policy, amending and subsequently repealing Council Directives 82/176/EEC, 83/513/ EEC, 84/156/EEC, 84/491/EEC, 86/280/EEC and amending Directive 2000/60/EC of the European Parliament and of the Council.

10. Eagleson P.S., 2002. Ecohydrology: Darwinian Expression of Vegetation Form and Function. Cambridge University Press.

11. EPA U.S. United States Environmental Protection Agency, 2003b. National Primary Drinking Water Regulations: Long Term 2 Enhanced Surface Water Treatment Rule - Toolbox guidance manual. June 2003. pp. 1-8.

12. European Commission, Directive 2000/60/EC of the European parliament and of the Council of 23 October 2000, establishing a Framework for Community Action in the field of Water Policy, Off. J. 
Eur. Commun. L 327, 2000 1-72.

13. Fabos J. G. 2004. International greenway planning: An introduction. Landscape and Urban Planning, 68, 143-146.

14. Feyen L., Barredo J.I., Dankers R. 2008. Implications of global warming and urban land use change on flooding in Europe. In: Feyen, J., Shannon, K., Neville, M. Eds., Water and Urban Development Paradigms - towards an Integration of Engineering, Design and Management Approaches. CRC Press, 217-225.

15. Fissore C., Baker L. A., Hobbie S. E., King J. Y., McFadden J. P., Nelson K. C., et al. 2011. Carbon, nitrogen, and phosphorus fluxes in household ecosystems in the Minneapolis-Saint Paul, Minnesota, urban region. Ecological Applications, 21 (3), 619-639.

16. Ford J.D., Smit B. 2004. A framework for assessing the vulnerability of communities in the Canadian Arctic to risks associated with climate change. Arctic 57 (4), 389-400.

17. Gallego J.L.R., Ordonez A. and Loredo J. 2002. Investigation of trace element sources from an industrialized area (Avilés, northern Spain) using multivariate statistical methods, Environ. Int., 27, 589-596.

18. Government Gazette 2010. The Greek Republic Issue Two Ref. Sheet 1909 December 8, 2010. No $51354 / 2641 /$ E103 Determination of Environmental Quality Standards (EQS) for concentrations of certain pollutants and priority substances in surface water in compliance with the provisions of Directive 2008/105/EC of the European Parliament.

19. Grayson R. B., Finlayson B. L., Gippel C. J., Hart B. T. 1996. The potential of field turbidity measurements for the computation of total phosphorus and suspended solids loads. Journal of Environmental Management, 473, 257-267.

20. Groffman P.M., Boulware N.J., Zipperer W.C. 2002. Soil nitrogen cycle processes in urban riparian zones. Environ. Sci. Technol. 36, 45-47.

21. Hatt B. E., Fletcher T. D., Walsh C. J., Taylor, S. L. 2004. The influence of urban density and drainage infrastructure on the concentrations and loads of pollutants in small streams. Environmental Management, 341, 112-124.

22. Hatzianestis I., Sklivagou E. 2002. Dissolved and Suspended Polycyclic Aromatic Hydrocarbons (PAH) in the North Aegean Sea. Mediterranean Marine Science, (S.1.), 3(1), 89-98. ISSN 1791-6763. http://dx.doi.org/10.12681/mms.261.

23. Jiang Yunfang, Shi Tiemao, Gu Xixi 2016. Healthy urban streams: The ecological continuity study of the Suzhou creek corridor in Shanghai. Cities 59, 80-94.

24. Karr J.R. 1999. Defining and Measuring River Health, Freshwater Biology, vol. 41. University of Washington, Seattle, USA, pp. 221-234.
25. Kasahara T., Hill A.R. 2008. Modeling the effects of lowland stream restoration projects on streamsurface water exchange, Ecol. Eng. 32, 310-319.

26. Kaushal S.S., Lewis W.M. Jr. 2005. Fate and transport of dissolved organic nitrogen in minimally disturbed streams of Colorado, USA, Biogeochemistry 74, 303-321.

27. Kim J.S., Yoon S.K., Moon Y.I. 2013. Development of rating curve for high water level in an urban stream using Monte Carlo simulation. J. Korean Soc. Civil Eng. 33 (4), 1433-1446.

28. Konrad C.P., Booth D.B. 2002. Hydrologic trends associated with urban development for selected streams in the Puget Sound Basin, western Washington, Water- Resources Investigations Report 02-4040, US Geological Survey, Denver, CO.

29. Larson M.G., Booth D.B., Morley S.A. 2001. Effectiveness of large woody debris in stream rehabilitation projects in urban streams, Ecol. Eng. 18, 211-226.

30. Leppard G. G., Munawar M. 1992. The ultrastructural indicators of aquatic ecosystem health. Journal of Aquatic Ecosystem Health, 4, 309-317.

31. Lowrance R. 1998. Riparian forest ecosystems as filters for non-point source pollution. In: Pace, M.L., Groffman, P. (Eds.), Successes, Limitations and Frontiers in Ecosystem Science. Springer-Verla, New York.

32. McKenna Jr, J.E. 2003. An enhanced cluster analysis program with bootstrap significance testing for ecological community analysis. Environ. Model. Softw. 18 (3), 205-220.

33. Melian Herrera J.A., Rodrıguez Dona J.M., Viera A. Suarez, Rendon Tello E., Valdes do Campo C., Arana J., Perez Pena J. 2000. The photocatalytic disinfection of urban waste waters. Chemosphere, 41, 323-327.

34. Meltem D., Azime T. 2017. Stream Daylighting' as an approach for the renaturalization of riverine systems in urban areas: Istanbul-Ayamama Stream Case. Ecohydrol. Hydrobiol., 17 (1), 18-32. http:// dx.doi.org/ 10.1016/j.ecohyd.2016.12.007.

35. Merz B., Hall J., Disse M., Schumann, A. 2010. Fluvial flood risk management in a changing world. Nat. Hazards Earth Syst. Sci 10(3), 509-527.

36. Miller S.W., Budy P., Schmidt J.C. 2010. Quantifying macroinvertebrate responses to in-stream habitat restoration: Applications of meta-analysis to river restoration, Rest. Ecol. 18: 8-19.

37. Negishi J. N., Noguchi S., Sidle R. C., Ziegler A. D., Nik A. R. 2007. Storm flow generation involving pipe flow in a zero-order basin of Peninsular Malaysia. Hydrological Processes, 21(6), 789-806.

38. Nelson K. C., Palmer M. A., Pizzuto J. E., Moglen G. E., Angermeier P. L.,Hilderbrand R. H., et al. 2009. Forecasting the combined effects of urban- 
ization and climate change on stream ecosystems: From impacts to management options. Journal of Applied Ecology, 46(1), 154-163.

39. Otto M. 1998. Multivariate methods. In: Kellner, R., Mermet, J.M., Otto, M., Widmer, H.M. (Eds.), Analytical Chemistry. Wiley-VCH, Weinheim.

40. Oven K.J., Curtis S.E., Reaney S., Riva M., Stewart M.G., Ohlemüller R., et al. 2012. Climate change and health and social care: defining future hazard, vulnerability and risk for infrastructure systems supporting older people's health care in England. Appl. Geogr., 33, 16-24.

41. Pinkham R. 2000. Daylighting: New Life for Buried Streams. Rocky Mountain Institute, Snowmass, $\mathrm{CO}, \mathrm{USA}$.

42. Platt H.R. 2006. Urban watershed management: sustainability, one stream at a time. Environ. Sci. Policy Sustain. Dev. 48 (4), 26-42.

43. Ragab R., Bromley J., Rosier P., Cooper J. D., Gash J. H. C. 2003. Experimental study of water fluxes in a residential area: 1. Rainfall, roof runoff and evaporation: The effect of slope and aspect. Hydrological Processes, 17(12), 2409-2422.

44. Schirmer M., Schuchardt B. 2001. Assessing the impact of climate change on the Weser estuary region: an interdisciplinary approach. Clim. Res. 18 (1), 133-140.

45. Schoonover J. E., Lockaby B. G., Helms B. S. 2006. Impacts of land cover on stream hydrology in the west Georgia piedmont, USA. Journal of Environmental Quality, 35(6), 2123-2131.

46. Shakunthala Bai, Shivanna Srikantaswamy, Doddaiah Shivakumar 2010. Urban Wastewater Characteristic and its Management in Urban Areas-A Case Study of Mysore City, Karnataka. India. J. Water Resource and Protection, 2, 717-726.

47. Skoulikidis N., Amaxidis Y., Bertahas I., Laschou S., Gritzalis K., 2006. Analysis of factors driving stream water composition and synthesis of management tools - a case study on small/medium Greek catchments. Sci. Total Environ. 362, 205-241.

48. Standard Methods for Examination of Water \& Wastewater 2005. Method 5530, 21st ed, American Public Health Association, Washington, DC, 5-43/5-47.

49. UNEP 1984. Manual for measuring oil and dissolved/dispersed petroleum hydrocarbons in marine waters and on beaches. Manuals and Guides, No. 13, UNESCO, Paris, 35p.

50. Wheeler S.M. 2000. Planning for metropolitan sustainability, J. Planning Educ. Res. 133-145.
51. Walsh C.J., Roy A.H., Feminella J.W., Cottingham P.D., Groffman P., Morgan M R.P. 2005. The Urban Stream Syndrome: Current Knowledge and the Search for a Cure, Cooperative Research Centre for Freshwater Ecology. Water Studies Centre and School of Biological Sciences, Monash University, Victoria, Australia.

52. Wardekker J.A., de Jong A., Knoop J.M., van der Sluijs J.P. 2010. Operationalising a resilience approach to adapting an urban delta to uncertain climate changes. Technol. Forecast. Soc. Change 77 (6), 987-998.

53. White L. J., Ladson A. R. 1999. An index of stream condition: Field manual. Melbourne: Department of Natural Resources and Environment.

54. Wu Jiayu, Stewart Timothy W., Thompson Janette R., Kolk Randall K., Franz Kristie J. 2015. Watershed features and stream water quality: Gaining insight through path analysis in a Midwest urban landscape, U.S.A. Landscape and Urban Planning 143, 219-229.

55. Wu J., Thompson J., Kolka R., Franz K., Stewart T. 2013. Using the Storm Water Management Model to predict urban headwater stream hydrological response to climate and land cover change. Hydrology and Earth System Sciences, 17, 4743-4758.

56. Yoon Sun-Kwon, Kim Jong-Suk, Moon YoungIl 2016. Urban stream overflow probability in a changing climate: Case study of the Seoul Uicheon Basin, Korea. Journal of Hydro-environment Research 13: 52-65.

57. Yoon S.K., Kim J.S., Moon Y.I. 2014. Integrated flood risk analysis in a changing climate: a case study from the Korean Han River Basin. KSCE J. Civil Eng. 18 (5), 1563-1571.

58. Zalewski, M. 2013. Ecohydrology: process-oriented thinking towards sustainable river basins. Ecohydrol. Hydrobiol. 13, 97-103.

59. Zbigniew W.K., Takeuchi K., 1999. Flood protection and management: quo vadimus? Hydrol. Sci. J. 44 (3), 417-432.

60. Zhang T., Feng H., Peng Z. 2002. Design and development of waterfront areas. Tongji University Press.

61. Zheng N., Takara K., Yamashiki Y., Tachikawa Y., 2009. Quantitative vulnerability analysis for regional flood hazard. Annu. Disaster Prev. Res. Inst. Kyoto Univ. (52B), 57-65.

62. www.atsdr.cdc.gov/toxprofiles/tp60-c6.pdf. Retrieved from the internet on 11/30/2017 